\title{
Social psychiatry and epidemiology
}

\author{
MICHAEL SHEPHERD
}

The term «social psychiatry» was first introduced by Southard (1917) and as a discipline it remains a warmly disputed hybrid. To one of its best-known contemporary advocates, for example, social psychiatry is "an "elastic" concept, to include all social, biological, educational and philosophical considerations which may come to empower psychiatry in its striving towards a society which functions whith greater equilibrium and with fewer psychological casualties» (Jones, 1968). Since the 1920s the representatives of this brand of social psychiatry have been provided with a theoretical basis by the more extravagant extensions of psychodynamic speculation. The widespread adoption of group psychotherapeutics in World War II was particularly significant in the UK, leading as it did to the nebulous but pervasive idea of the "therapeutic community» which has been so widely linked to social aggregates of all types, varying from the family to institutions to the community at large. The global influence of these ideas was reflected in the immediate post-war activities of the World Health Organization and in 1959 an Expert Committee on Mental Healt went so far as to define social psychiatry as nothing less than «the preventive and curative measures which are directed towards the fitting or an individual for a satisfactory and useful life in terms of its own environment» (WHO, 1959).

\section{HISTORICO-SCIENTIFIC BACKGROUND}

The scientific study of the social aspects of psychiatry has a longer, more sober history. Its roots

\footnotetext{
Indirizzo per la corrispondenza: Professor M. Shepherd, Institute of Psychiatry, University of London, De Crespigny Park, Denmark Hill, London SE5 8AF, U.K.
}

can be traced to the work of nineteenth and early twentieth century clinicians, but its development was to depend on the systematic application of the epidemiological method to non-infectious disease over the past 30 years. An historical landmark in the study of the epidemiology of mental disorders was a conference organized under that title by the Millbank Memorial Fund in 1949, with the objective of exploring common ground between public health workers and psychiatrists. At that meeting Gruenberg (1950) indicated the scope of the field in his categorization of a bibliography compiled for the occasion. Apart from problems of method his classification of 363 references was as follows: diagnosis and nomenclature; statistical problems and computations of expectancy; data relating to hospitalized cases, mainly from administrative records, measures of morbidity, including prevalence in populations, surveys, military drafts, and the like; studies based upon scrutiny of case records; epidemics and discrete outbreaks of particular' disorders varying from a few moments to a few hundred years; from time to time; from place to place; among migrant and non-migrant populations; by age and sex; from society to society (and from culture to culture); in different psychological or social climates; related to physical diseases and injuries; related to premorbid experiences and personal characteristics; related to genes; position in social structure related to mental disorders; occupational psychopathology; natural history of mental disorders elucidated by epidemiological methods; evaluation of prevention and control programmes by epidemiological methods.

Its is evident from this list that most of the basic themes of epidemiological psychiatry were familiar to investigators of mental illness over the past 150 years. Epidemics of abnormal behaviour have long been recognized, and not a few of the older psy- 
chiatrists were pre-occupied with such topics as socioeconomic change, occupation, isolation and migration.

Kraepelin, for example, in espressing his dissatisfaction with the routine methods of clinical research and his interest in "comparative psychiatry", was clearly moving in the direction of epidemiological inquiry when he wrote: «By comparing a large series of observed cases we can study first, how far such general characteristics as sex, age, and culture can influence the clinical picture: in the same way we can also examine how factors like occupation, climate and the general and personal circumstances of living may colour the clinical patterns encountered" (Kraepelin, 1920).

The development of intelligence testing and the early studies of suicide anticipate the potential contributions of the psychologists and the sociologists to epidemiological inquiry (Lewis, 1929; Durkheim, 1951), and the classical series of studies by Goldberger on pellagra demonstrate how the skills of a professional epidemiologist could be applied to mental illness (see Shepherd, 1978).

The first, and most important, function of epidemiological psychiatry has been to bring together seemingly diverse activities undertaken by workers in different disciplines, so as to enable the nature and extent of common ground to become apparent. The assumptions underlying the epidemiological approach to mental disorder have now been authoritatively endorsed by a World Health Organization Committee, whose report concluded that «... the problems of studying personal susceptibility and the modifying effects of the environment or habit on the risks of attack were essentially similar in the comunicable diseases and in other kinds of human illness. Consequently, the methods which had been used so successfully in uncovering the origins and mode of spead of disease associated with microbial infection came to be increasingly applied to the study of mental disordes and the use of the term "epidemiology" to imply the study of their distribution and behaviour in differing conditions of life in human comunities became widely accepted» (WHO, 1960).

\section{APPLICATIONS OF EPIDEMIOLOGICAL METHODS}

Within this broad framework, however, the application of epidemiological methods to the study of mental disorder has been seriously hampered by a variety of methodological problems, not least those associated with case-definition. For any form of epidemiological inquiry the investigator must be able to characterize sick people and to distinguish between them and healthy members of the population. This requirement has proved to be a major obstacle in psychiatry, in which objective indices of illness are present infrequently and few disagnostic tests are available. In consequence, operational definitions have all too often to be constructed for individual studies. The purpose of such definitions is not to replace clinical criteria but to improve the level of consistency among observers, especially regarding borderline cases, thereby diminishing inter-observer variation.

During the past decade and increasing awareness of the importance of this issue has resulted in a variety of attempts to focus attention on the diagnostic process and its vagaries. These support the conclusion reached by Blum (1962) on the basis of his careful review of problems associated with case-finding in psychiatry: «The interview is the main tool of the psychiatrist - the means he uses to arrive at a diagnosis. In is also the ultimate criterion against which other means of identifying psychiatric disorder are validated». Experimental studies of the psychiatric interview have demonstrated three sources of disagreement and error between observers (Shepherd et al., 1968). These comprise, first, variations at the level of clinical observation and perception; second, variations in inferences drawn from these observations; and, third, variations in the nosological schemata employed by individual clinicians.

With regard to the first two factors of this triad - that is, observation and inference derive therefrom - the range of disagreement between psychiatrists can be substantially narrowed by the use of standardized interviews which incorporate symptomratings. While these instruments cannot in themselves provide a diagnosis for individual patients, they can be useful in facilitating communications between investigators and giving greater meaning to comparisons. Their construction demands careful analysis of the diagnostic process and the type of condition being investigated.

Increased accuracy in labelling and more precision in terminology can also be aied by the construction of glossaries in such a way as to reduce ambiguity. A number of national glossaries have been published, each of them illustrating all too clearly the different concepts employed in different countries and indicating the need for international agreement. 
The pratical importance of this question has been sharply illustrated by the very large differences between the schizophrenic rates reported in the USA and UK, a contrast largely attributable to diagnostic usage (Cooper et al., 1972). Mention should also be made of the trend towards multi-axial classification as a method of reducing the need to compress clinical phenomena and causal factors artificially into one category (Rutter et al., 1975).

\section{CONCLUSION}

Despite the difficulties, an impressive body of epidemiological research has already been conducted. Perhaps its most impressive achevement has been to demonstrate the nature and extent of psychiatric illness in the community. This large extra-mural pool of morbidity poses a public health challenge of the first order, and one which involves particularly the general practitioner who largerly assumes responsibility for the identification and care of the majority of mentally sick people (Shepherd et al., 1981). This large area of common ground between social psychiatry and general practice constitutes a major field for collaborative inquiry within any form of National Health Service.

\section{REFERENCES}

Blum R. H. (1962). Case identification in psychiatric epidemiology: methods and problems. Millbank Memorial Fund Quarterly $40,253-288$.

Cooper J. E., Kendell R. E., Gurland B. J., Sharpe L., Copeland J. R. M. \& Simon R. (1972). Psychiatric Diagnosis in New York and London. Oxford University Press: London.

Durkheim E. (1951). Suicide: A Study in Sociology (translated by J. A. Spauldin and G. Simpson). Free Press: Glencoe, Ill.

Gruenberg E. (1950). Epidemiology of Mental Disorder. Millbank Memorial Fund: New York.

Jones M. (1968). Social Psychiatry in Practice. Penguin Books: Harmondsworth.

Kraepelin E. (1920): Die Erscheinungsformen des Irreseins. Zeitschrift fuer die Gesamte Neurologie und Psychiatrie 62, 1-29.

Lewis E. O. (1929). Report on the Investigation into the Incidence of Mental Deficiency in Six Areas, 1925-27. Board of Education and Board of Control Mental Deficiency Committee Report, pt 4. HMSO: London.

Rutter M., Shaffer D. \& Shepherd M. (1975). A Multi-axial Classification of Child Psychiatric Disorders. WHO: Geneva.

Shepherd M. (1978): Epidemiology and clinical psychiatry. British Journal of Psychiatry 133, 289-298.

Shepherd M., Brooke E. M., Cooper J. E. \& Lin T. (1968). An Experimental Approach to Psychiatric Diagnosis. Acta Psychiatrica Scandinavica, Supplementum No. 201. Munksgaard: Copenhagen.

Shepherd M., Cooper B., Brown A. C. \& Kalton G. W. (1981). Psychiatric Illness in General Practice (second edition). Oxford University Press: Oxford.

Southard E. E. (1917). Alienists and psychiatrists. Mental Hygiene 1, 567-571.

World Health Organization (1959). Social Psychiatry and Community Attitudes. Technical Reports Series, No. 177. WHO: Geneva.

World Health Organization (1960). Epidemiology of Mental Disorders. 8th Report of the Expert Committee on Mental Health. WHO: Geneva. 


\section{SorprendenteMente}
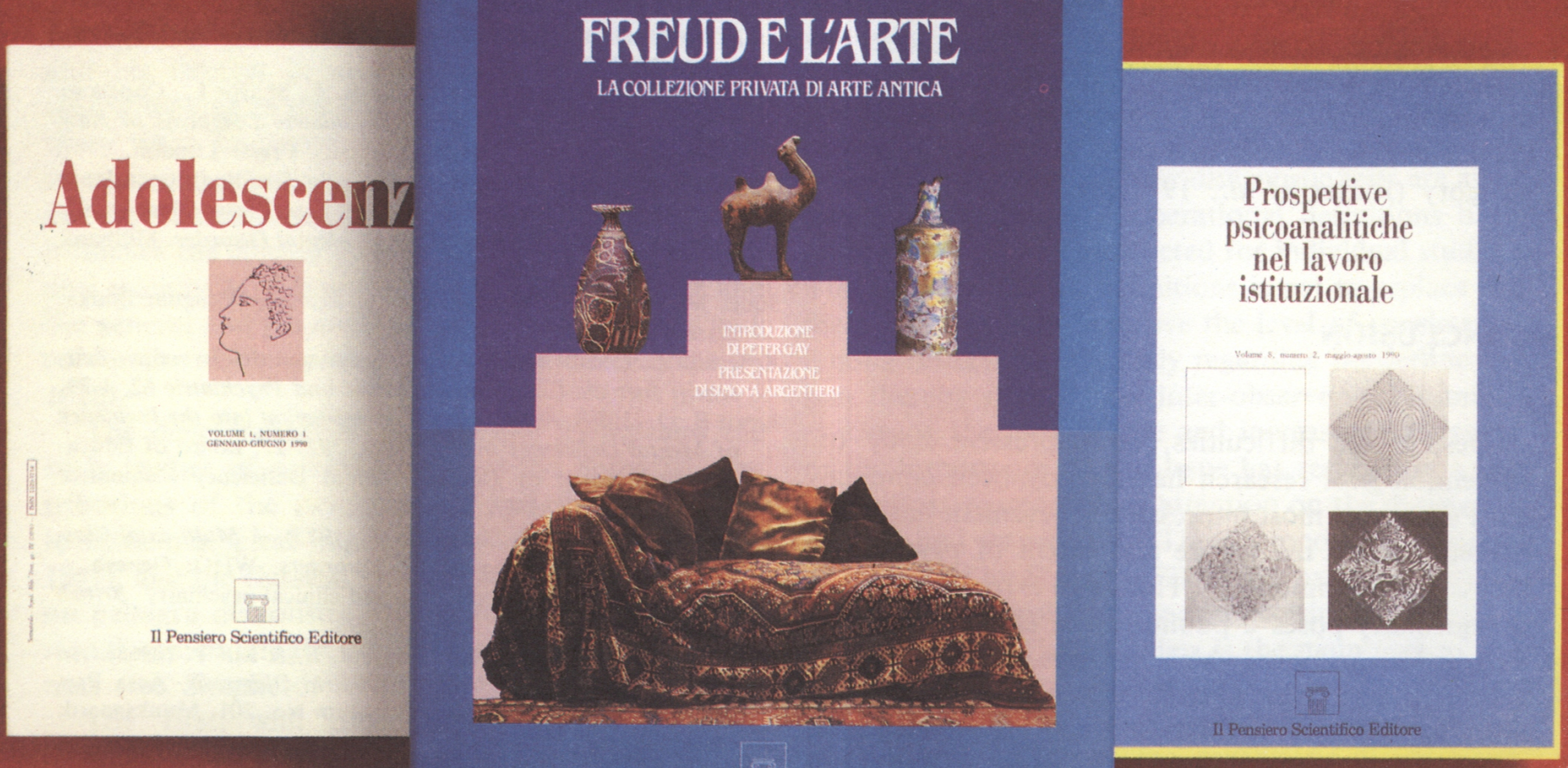

II Pensiero Scientifico Editore
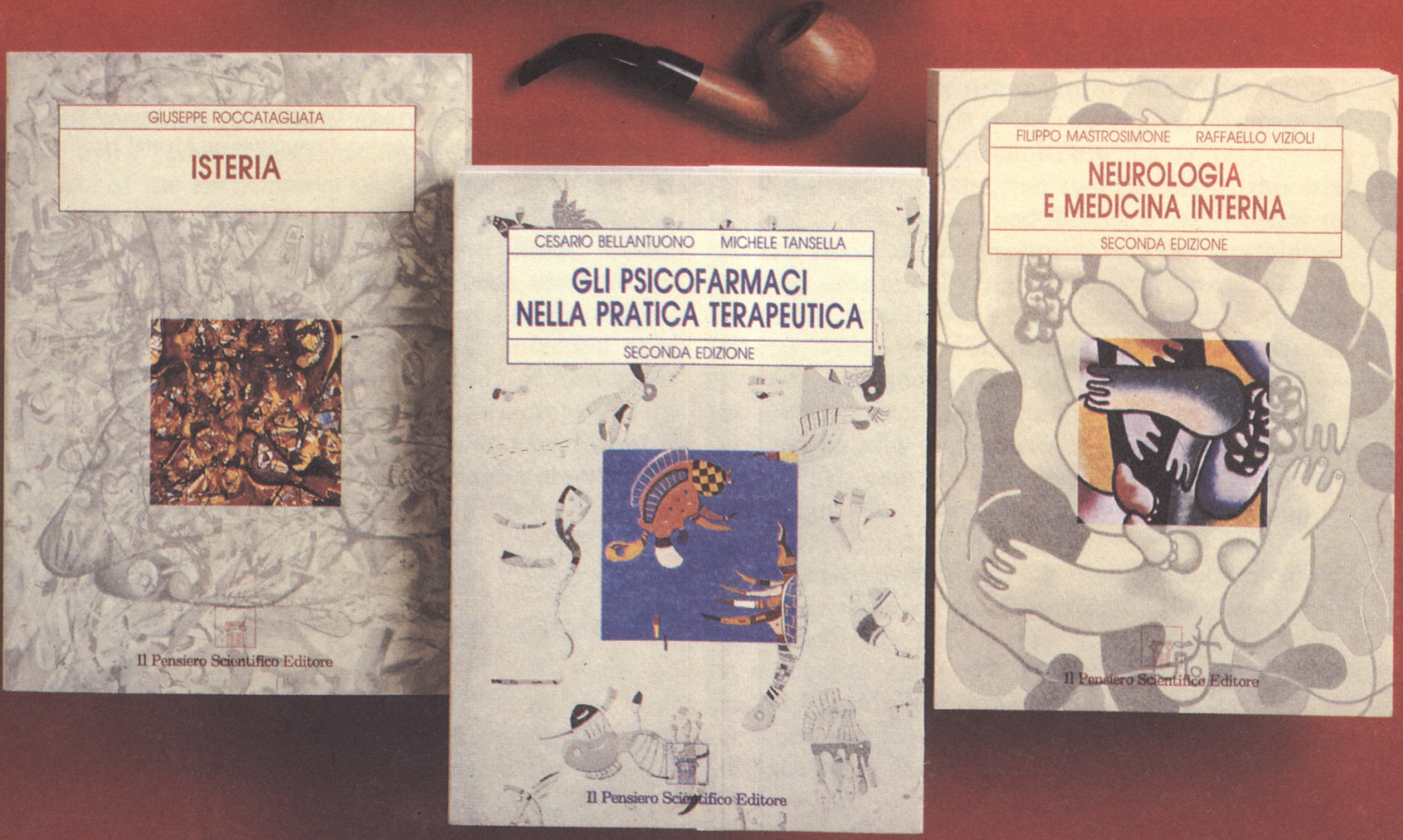

Il Pensiero Scientifico Editore 